\title{
A Hybrid Micro-Simulator for Determining the Effects of Governmental Control Policies on Transport Chains
}

\author{
Markus Bergkvist ${ }^{1}$, Paul Davidsson ${ }^{1}$, Jan A. Persson ${ }^{2}$, and Linda Ramstedt ${ }^{2}$ \\ ${ }^{1}$ Blekinge Institute of Technology, Department Systems and Software Engineering, \\ 37225 Ronneby, Sweden \\ ${ }^{2}$ Blekinge Institute of Technology, Department Systems and Software Engineering, \\ 37424 Karlshamn, Sweden \\ \{Markus.Bergkvist, Paul. Davidsson, Jan.Persson, Linda.Ramstedt\}@bth. se
}

\begin{abstract}
A simulation-based tool is described which will be used to investigate how the actors in a transport chain are expected to act when different types of governmental control policies are applied, such as, fuel taxes, road tolls, vehicle taxes and requirements on vehicles. The simulator is composed of two layers, one layer simulating the physical activities taking place in the transport chain, e.g., production, storage, and transports of goods, and another layer simulating the different actors' decision-making processes. The decision layer is implemented by a multi-agent system where each agent corresponds to a particular actor and models the way it acts in different situations. The simulator will be used for analyzing the costs and environmental effects, and will in this way provide guidance in decision making regarding control policies. In addition, it will be possible for companies to use the simulator in order to determine cost-effective strategies given different (future) scenarios.
\end{abstract}

\section{Introduction}

This paper describes a simulation-based tool with the aim to investigate how the actors in a transport chain are expected to act when different types of governmental control policies, such as, fuel taxes, road fees, vehicle taxes and requirements on vehicles, are applied. The policy making is driven by a desire to attain a sustainable environment (by reducing emissions, noise, accidents, and so on) and to achieve sustainable economical development.

From a societal perspective, the simulator will be used to analyze the total costs and environmental effects of a transport chain and in this way provide guidance in decision making regarding control policies. The intention is that such analyzes will complement those made using existing macro-models. In addition, it will be possible for businesses to use the simulator in order to determine cost-effective strategies given different (future) scenarios.

In the next section we further motive the need for the type of tool suggested and review some related work. We then describe the problem domain and the structure of the simulator. A discussion and pointers to future work concludes the paper. 


\section{Background}

The importance of being able to predict the effects of governmental control policies can be illustrated by the marginal cost principle. According to this principle, the external costs of transports, such as, emissions, road wear, congestion, noise, accidents etc., should be internalized. It has been argued that the current fees and taxes for heavy transports do not correspond to the actual external costs caused by these transports [5]. To apply the marginal cost principle it is necessary to change some taxes, fees, or regulations. But in order to know which action(s) to take, it is important to have deep knowledge regarding the effects of these actions, i.e., how the different actions will change the behavior of the actors involved in transport chains. This is important in order for policy makers to take a long term perspective supporting sustainable growth of trade and industry. From the perspective of the actors in a transport chain, they need to develop strategies for acting given different future implementations of control policies.

\subsection{Existing Simulation Models for Transport Systems}

Traditionally, the effects of control policies have been studied using macro-level models, such as SAMGODS (SAMPLAN) [8], ASTRA [1] and SISD [6]. This type of models are taking a societal perspective and are based on aggregated coursegrained data on the national level. A problem with these models is that they do not take the logistical processes into account, e.g., choice of carrier type and inventory strategies, and thus fail to model the level where the decisions regarding the actual transports are taking place. Models that take logistical aspects into consideration are for example SMILE [9], GoodTrip [2] and SLAM [6]. However, these models cannot take specific properties of individual transport chains into account. Due to (increased) cooperation between actors in transport chains (e.g., producers, customers, transport operators), there exists a significant flexibility of how to carry out their operations given different control policies. We believe that more precise predictions regarding the effects of control policies can be achieved using micro-level models, i.e., transport chain level models, that capture also the decision making of the actors in the logistical processes.

\subsection{Multi Agent Based Simulation for Policy Making}

As Multi Agent Based Simulation, MABS, and other micro simulation techniques, explicitly attempts to model specific behaviors of specific individuals, it may be contrasted to macro simulation techniques that are typically based on mathematical (equation-based) models where the characteristics of a population are averaged together and the model attempts to simulate changes in these averaged characteristics for the whole population. Thus, in macro simulations, the set of individuals is viewed as a structure that can be characterized by a number of variables, whereas in micro simulations the structure is viewed as emergent from the interactions between the 
individuals. According to Parunak et al. [7] “....agent-based modeling is most appropriate for domains characterized by a high degree of localization and distribution and dominated by discrete decision. Equation-based modeling is most naturally applied to systems that can be modeled centrally, and in which the dynamics are dominated by physical laws rather than information processing." Obviously, transport systems fulfill all the characteristics of domains appropriate for agent-based modeling.

As an example of an application of MABS for policy making, consider Downing et al. [4], who have used it in the context of climate policy and climate change. A prototype agent-based integrated assessment model was proposed for water issues like drought, flood etc. where the social relations that support the effectiveness of exhortation are described. Downing et al. argue that MABS is well-suited for this purpose since agents represent the behavior of different actors, here policy makers and households, and the interaction between the agents can therefore be described and evaluated. Also, since MABS can represent different grain, couplings to macro-models can be done.

\section{The Problem Domain}

The general area investigated is decision support for public policy makers in the area of transportation and traffic. In particular we study the question: What would the consequences be in a transport chain ${ }^{1}$ given a certain policy? We envision a simulation-based decision support system were a policy maker is able to experiment with different types of fees, taxes, requirements on vehicles, etc. and get feedback from the system regarding the predicted effects of these policies.

The consequences of public control policies on transport chains are closely connected to the decisions made within the chain, such as, choosing mode of transportation, carrier size, when to transport, which quantities to transport. These decisions are made by different actors at different levels in the chain and may have implications on the system which are rather hard to anticipate.

In general a transport chain can be organized in a number of different ways with respect to the owner of the products at different locations and to the decision makers organizational belonging, e.g., the transport could be carried out by either the seller, buyer or third party logistics operator. The decision making in transport chains is subject to both short- and long-term planning implying that the time dimension of the decisions needs to be considered when modeling the transport chains. We will assume that the decision makers (actors) are cost minimizers locally. However, we incorporate the objective of cost minimization at a system level by allowing market-based cooperation between the simulated actors.

The input to the simulator is:

- $\quad$ the transport tasks, i.e., a sequence of customer requirements

\footnotetext{
${ }^{1}$ We avoid the term supply chain, since it implies indirectly that a customer view is taken, i.e. to supply a customer, rather than a system view. Also, our focus is on transports, whereas production and consumption provides the context in which the transports take place.
} 
- the available transport resources and their characteristics, such as costs, capacity, and environmental impact

- the available production resources and their characteristics

- the available infrastructure, e.g., road and rail networks

- the location of producers, customers, storages, etc.

Given this task, the user of the simulator will be able to experiment with different control policies, by varying a number of parameters corresponding to different taxes, fees, regulations etc.

The output will then include (among other things):

- performed transport operations

- the estimated external costs (including environmental costs)

- $\quad$ society revenue (from taxes, fees, etc)

- the internal costs

- customer satisfaction measured in terms of reliability of deliveries and quality of products.

\section{The Simulator}

As mentioned earlier we have chosen a hybrid approach, where an agent-based approach has been used to simulate the decision-making activities, and a more traditional object-oriented micro-level approach has been used to simulate the physical activities. This is illustrated in Fig 1 and further described in the remaining part of this section.

\subsection{Physical Simulator}

The physical simulator is based on the description of the production and distribution network suggested by Davidsson and Wernstedt [3]. It simulates the physical level of the production and distribution of commodities, whereas the decisions for what to produce, where to store the commodities, fleet management, etc. are simulated by the decision-making simulator.

There are four basic types of entities in the simulator that makes up the production and distribution: nodes, links, transport carriers and commodities. A node is a producer, an internal distribution node, or a customer, and has the following attributes:

- production capacity for each commodity,

- production level (dynamic, i.e., the value may change during the simulation),

- storage capacity (volume) for each commodity type,

- inventory level (dynamic),

- load time for each carrier type, and

- unload time for each carrier type. 
Decision maker simulator

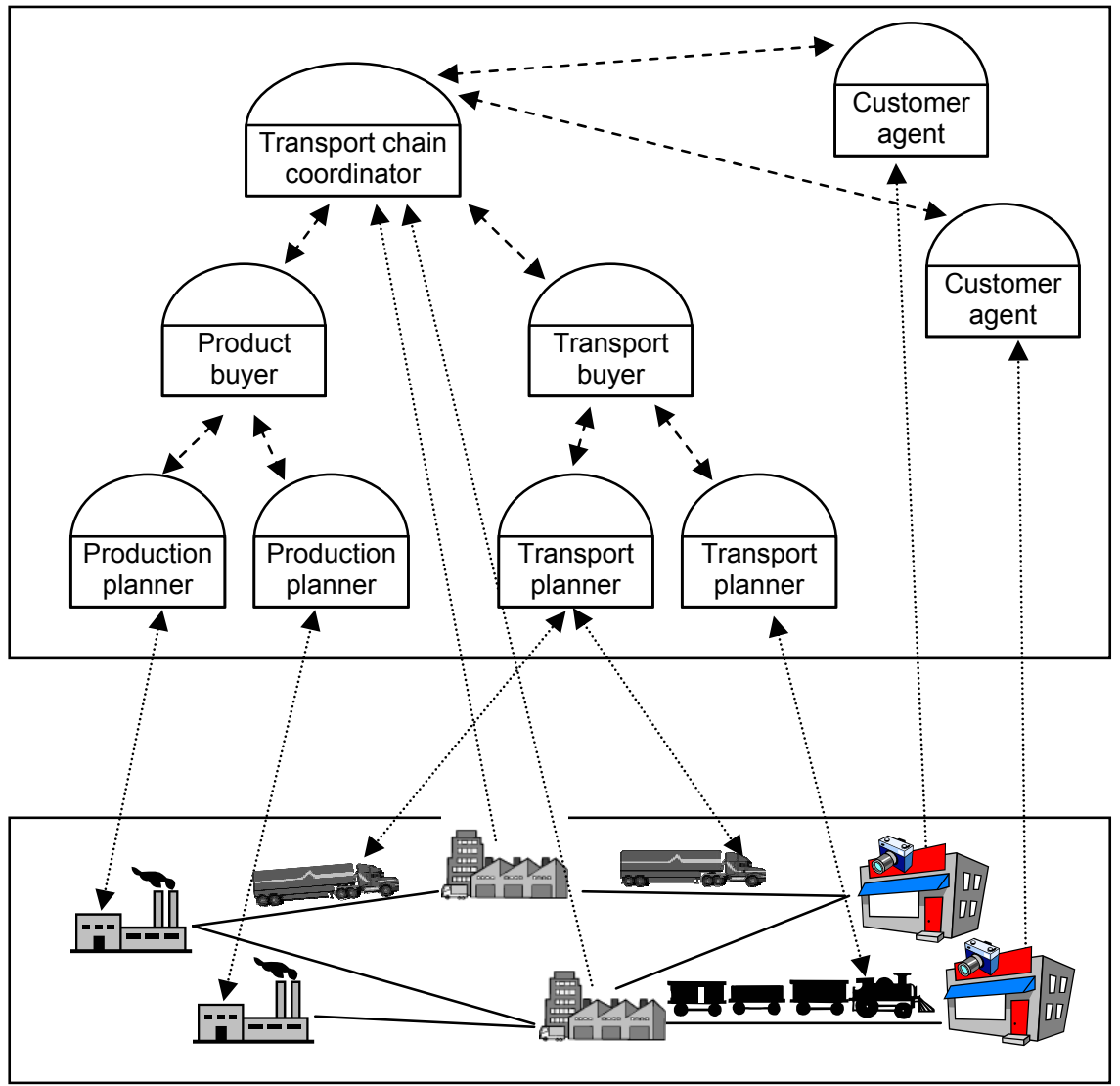

Physical simulator

Fig. 1. The two layers of the simulator.

A link connects a pair of nodes in the distribution network and acts as a distribution channel for the transport carriers. A link has the following attributes:

- connected pair of nodes,

- mode of transportation,

- length, and

- maximum distribution speed.

A transport carrier is an entity that performs a transport along a link and has the following attributes:

- carrier type (Each type is associated with a particular mode of transportation.),

- volume capacity for each commodity type, 
- location (dynamic),

- load (dynamic),

- maximum speed,

- delay probability distribution,

- transport cost (as a combination of fixed and proportional costs), and

- environmental impact (as a combination of fixed and proportional impact).

A commodity is produced at nodes and transported via links by transport carriers and have the following attributes:

- commodity type (based on storage requirements),

- production cost,

- production time,

- mass,

- volume, and

- quality (dynamic, based on age).

The activities in the physical simulator can be controlled during run-time through a number of commands. There are commands available to start a production batch, load and unload commodities from a transport carrier, initiate a transport or consume commodities. Commands that are sent to the simulator are placed locally at the target entity in a first-in-first-out queue.

The available commands, their constraints and expected outcomes are:

- $\quad \operatorname{Manufacture}(n, c, s)$ Adds a new command to the command queue of node $n$ to start a new production batch of commodity $c$ of size $s$. The command is executed if the node has the required production capacity. The time until the batch is completed is determined by the production time. When the batch is completed the new commodities are placed in storage at $n$.

- $\operatorname{Load}(v, c, s, n)$ Adds a new command to the command queue of transport carrier $v$ to load the quantity $s$ of commodity $c$ from the storage of node $n$. The command is executed if the transport carrier is located at node $n$. It then requests the commodities from the node which returns the commodities (if available) and the time it takes to load them.

- $\operatorname{Unload}(v, c, s, n)$ Adds a new command to the command queue of transport carrier $v$ to unload the quantity $s$ of commodity $c$ to the storage of node $n$. Works similar to the Load command with the difference that a request to unload is sent to the node.

- $\operatorname{Dispatch}(v, e)$ Adds a new command to the command queue of transport carrier $v$ to initiate a transport using link $e$. The command can only be executed if the carrier is at either of the nodes connected by $e$, and is not un/loading.

- $\quad$ Consume $(n, c, s)$ Adds a new command to the command queue of the node $n$ to consume quantity $s$ of commodity $c$ from the storage of node $n$.

In addition, it is possible to read the attributes of all entities. 


\subsection{Decision-making Simulator}

We have identified a number of important roles in a transport chain, which are described in the table below.

\begin{tabular}{|c|c|c|c|}
\hline $\begin{array}{l}\text { Decision } \\
\text { maker }\end{array}$ & Decisions and actions & Based on & Goal \\
\hline $\begin{array}{l}\text { Customer } \\
\text { agent }\end{array}$ & $\begin{array}{l}\text { Makes requests of products } \\
\text { with respect to quantities, } \\
\text { time of delivery (or time } \\
\text { window), and quality level. }\end{array}$ & $\begin{array}{l}\text { Anticipated customer de- } \\
\text { mand and inventory levels } \\
\text { at customer. }\end{array}$ & $\begin{array}{l}\text { Mediate customer } \\
\text { requirements in the } \\
\text { most accurate way } \\
\text { that is possible. }\end{array}$ \\
\hline $\begin{array}{l}\text { Transport } \\
\text { chain coor- } \\
\text { dinator }\end{array}$ & $\begin{array}{l}\text { Decides how much should } \\
\text { be bought from producers } \\
\text { and how much should be } \\
\text { taken from storages. Makes } \\
\text { requests to product and } \\
\text { transport buyers. }\end{array}$ & $\begin{array}{l}\text { Requests from the customer } \\
\text { agents, intermediate inven- } \\
\text { tory levels, and transport } \\
\text { and production opportuni- } \\
\text { ties. }\end{array}$ & $\begin{array}{l}\text { Satisfy the cus- } \\
\text { tomer requirements } \\
\text { at the lowest possi- } \\
\text { ble cost. }\end{array}$ \\
\hline $\begin{array}{l}\text { Product } \\
\text { buyer }\end{array}$ & $\begin{array}{l}\text { From which producer } \\
\text { should the products be } \\
\text { bought? Makes request of } \\
\text { production to production } \\
\text { planners. }\end{array}$ & $\begin{array}{l}\text { Requests from transport } \\
\text { chain coordinator. Bids } \\
\text { from producers (production } \\
\text { planners), including prices, } \\
\text { deadlines, quality of product } \\
\text { etc. }\end{array}$ & $\begin{array}{l}\text { Satisfy the product } \\
\text { requirements at the } \\
\text { lowest price possi- } \\
\text { ble (given the } \\
\text { constraints). }\end{array}$ \\
\hline $\begin{array}{l}\text { Production } \\
\text { planner }\end{array}$ & $\begin{array}{l}\text { What is the best bid that the } \\
\text { producer can provide? } \\
\text { Gives production orders to } \\
\text { the producer. }\end{array}$ & $\begin{array}{l}\text { Production capacity, storage } \\
\text { levels (at the production } \\
\text { site). }\end{array}$ & $\begin{array}{l}\text { Minimize produc- } \\
\text { tion costs. }\end{array}$ \\
\hline $\begin{array}{l}\text { Transport } \\
\text { buyer }\end{array}$ & $\begin{array}{l}\text { From which transport op- } \\
\text { erator should the transport } \\
\text { be bought? Makes request } \\
\text { of transports to transport } \\
\text { planners. }\end{array}$ & $\begin{array}{l}\text { Requests from transport } \\
\text { chain coordinator. Bids } \\
\text { from transport operators } \\
\text { (transport planners), includ- } \\
\text { ing prices, quality of trans- } \\
\text { port, etc. }\end{array}$ & $\begin{array}{l}\text { Satisfy the trans- } \\
\text { port requirements } \\
\text { at the lowest price } \\
\text { possible (given the } \\
\text { constraints). }\end{array}$ \\
\hline $\begin{array}{l}\text { Transport } \\
\text { planner }\end{array}$ & $\begin{array}{l}\text { What is the best bid that the } \\
\text { transport operator can } \\
\text { provide? Assigns tasks to } \\
\text { transport carriers (fleet } \\
\text { management). }\end{array}$ & $\begin{array}{l}\text { Status (availability, posi- } \\
\text { tion, etc) of the transport } \\
\text { carriers controlled by the } \\
\text { operator. }\end{array}$ & $\begin{array}{l}\text { Minimize transport } \\
\text { costs. }\end{array}$ \\
\hline
\end{tabular}

There are many possible mappings between organizations and the different decision making agents. In the extreme case, all decision makers belong to the same organization for a transport chain, e.g., petroleum companies. Another extreme, is where all decision makers belongs to different organizations. Also, intermediate arrangements exist such as one of the real world cases in the project. Below is some mappings between agents and organizations suggested: 
- The customer agent might be a retailer or a producer, with the goal to buy a desired quantity of goods to the lowest price and delivered at a desired time. However, this agent can typically accept (to a reduced price) to receive the products earlier than required and hence store the product until needed.

- The transport chain coordinator might, for example, be a planner within a larger company or a third or fourth party logistics operator.

- The product buyer is often connected to the organization which hosts the transport chain coordinator. However, it can be independent, for example, in case the transport chain coordinator is a third party logistics operator.

- The production planner belongs typically to the producing company.

- The transport buyer might belong to different type of organizations, for instance, the transport buyer might belong to the same organization as the customer or as the transport chain operator.

- The transport planner typically belongs to the organization owning and controlling the transport carriers.

In a studied transport chain within the food industry, a number of decision making agents: transport chain coordinator, product buyer, production planner, and transport buyer, are all associated with the producing company. The customer and the transport planner agents are associated with the customer and the transport operating company, respectively.

The suggested hierarchical design of the decision maker simulator allows for the study of different levels of cooperation. In an extreme, but rather common, case, the agents have pure local objectives (local cost minimizer) with virtually no sharing of information. In another extreme case, they are fully cooperative with the objective of minimizing total cost of the system.

The decision-making simulator primarily models operational decisions. Strategic decisions, such as buying or selling of vehicles or storage capacity, are not explicitly modeled. However, these decisions may be accounted for by the user of the simulator or directly in a more advanced version of the simulator by extending the domain of decision that the agents can make.

\section{Conclusions and Future Work}

We have outlined a hybrid micro-level simulator which is currently being developed. It models the physical activities as well as decision making activities taking place in transport chains. We will use this simulator in order to study the effects of different governmental control policies. This will be done in several steps with increasing complexity:

1. Consider only the transport selection issues (focusing on the decisions made by the Transport buyer), assuming that sufficient amount of products and carriers always are available. 
2. Considering also fleet management issues (focusing on the decisions made by the Transport planners), but still assuming that sufficient amount of products always are available.

3. Considering also production planning (focusing on the decisions made by the Production planners), but assuming that transports and production are independently planned.

4. Consider cooperation between producers and transporters (focusing on the decisions of the Transport chain coordinator and its interaction with the production and transport buyers).

Once step four is completed, different levels of cooperation between actors can be studied. Hence the effects of governmental control policies can be studied in relation to level of cooperation.

A number of characteristic scenarios will be studied using the simulator. In-depth case studies will be made on a set of transport chains involving FoodTankers and Karlshamns AB (see below). Validation of the simulation model will be carried out partly through these case studies, and partly though close cooperation with SIKA (the Swedish Institute for Transport and Communications Analysis). SIKA has much experience in the area and access to vast amount of data concerning the Swedish transport and traffic systems. As they also are a potential user of the simulator, they are participating in the requirements analysis.

In order to generalize the results so that the effects in other types of transport chains can be predicted, a number of relevant logistic factors have been identified. Examples of logistic factors are: geographical spread of producers and customers, transported volumes, value to weight (or volume) ratio of the goods, possibility to store the goods, available transport modes.

\section{Acknowledgements}

This work is carried out within the project "Effects of Governmental Control Policies in Transportation Chains: A Micro-level Study" (see www.ipd.bth.se/stem), which is mainly financed by VINNOVA, the Swedish Agency for Innovation Systems, which integrates research and development in technology, transport and working life. VINNOVA's mission is to promote sustainable growth by financing RTD and developing effective innovation systems. Two companies are involved in the case study, FoodTankers which provides services in the form of tanker transport, and Karlshamns AB which is one of the world's leading producers of vegetable oils and fats. In addition, the project is supported by an expert committee including experts from SIKA and the Swedish Environmental Protection Agency (via the MiSt research programme). 


\section{References}

1. ASTRA - Assessment of Transport Strategies, Final Report, Deliverable to EU DGTREN, ASTRA Consortium, Karlsruhe, ASTRA, 2000. (Available at http://www.iww.uni-karlsruhe.de/ASTRA/ASTRA_Final_Report.pdf)

2. Boerkamps, J., van Binsbergen, A., GoodTrip - A New Äpproach for Modelling and Evaluation of Urban Goods Distribution, Urban Transport Conference, $2^{\text {nd }} \mathrm{KFB}$ Research Conference, Lund, Sweden, 7-8 June 1999.

3. Davidsson, P., and Wernstedt, F.: A framework for evaluation of multi-agent system approaches to logistics network management. To appear in Multi-Agent Systems: An Application Science, Kluwer, 2004.

4. Downing, T.E., Moss, S., Pahl-Wostl, C.: Understanding Climate Policy Using Participatory Agent-Based Social Simulation, In Moss, S. and Davidsson, P. (eds.) Multi-Agent-Based Simulation, Springer, 2001.

5. Hesselborn P.-O., Swahn, H., Ekonomiska styrmedel i transportpolitiken - Förslag till utveckling av den svenska modellen, SIKA Dokument 1998:1, Presented at the University of Aalborg at the conference "Trafikdage i Aalborg"

6. ME\&P - WSP, DfT Integrated Transport and Economic Appraisal, Review of Freight Modelling, 2002 (http://www.dft.gov.uk/stellent/groups/ dft_transstrat/documents/page/dft_transstrat_508058.pdf)

7. Parunak H.V.D., Savit R., Riolo R.L.: Agent-Based Modeling vs. Equation-Based Modeling: A Case Study and Users' Guide. In Sichman, J.S., Conte, R., Gilbert, N. (eds.), Multi-Agent Systems and Agent-Based Simulation, pp. 10-26, Springer, 1998.

8. Swahn, H.: The Swedish model systems for goods transport - SAMGODS. A brief introductory overview. SAMPLAN Report 2001:1, SIKA, 2001.

9. Tavasszy, L.A., van de Vlist, M., Ruijgrok, M., van de Rest, J.: Scenario-wise analysis of transport and logistics systems with a SMILE, 8th World Conference on Transport Research, Antwerp, Belgium, 1998. 